\title{
WAYFINDING E OS OBSTÁCULOS DA DEFICIÊNCIA VISUAL
}

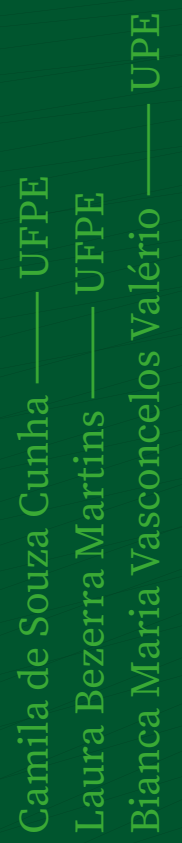




\section{INTRODUÇÃO}

Muitos instrumentos vêm sendo criados no Brasil com a finalidade de promover autonomia às pessoas com deficiência visual, por meio de recursos físicos, ambientais e informacionais acessíveis e aplicados em diversos contextos sociais. No entanto, em relação à esfera da educação inclusiva, observa-se que alguns questionamentos e reflexões precisam ser levantados, visto que, segundo cruzamentos de dados fornecidos pelo IBGE (2013) e pelo INEP (2017a, 2017b), é possível observar que, no Brasil, pessoas sem deficiência possuem 24 vezes mais acesso ao ensino superior do que pessoas com deficiência visual (cegueira e baixa visão).

Tais dados impulsionam, então, a uma reflexão sobre os possíveis motivos que impedem ou dificultam o acesso desse grupo de 
indivíduos a esse nível de educação. Entre os vários fatores observados, destaca-se a fragilidade causada na autonomia dessas pessoas, devido à existência de obstáculos quanto à informação espacial nos ambientes educacionais, gerados pela ausência, mau posicionamento, excesso ou mau dimensionamento dos elementos de sinalização (Cunha, 2019).

Diante disso, o enfoque dessa pesquisa parte da demanda gerada pelas necessidades informacionais das pessoas com deficiência visual em ambientes construídos, buscando compreender como esses indivíduos formam suas estratégias de navegação, como consequência das informações encontradas nos ambientes.

Assim, esta pesquisa justifica-se na abertura dessa problemática para investigações acerca do tema e nas experiências e dificuldades enfrentadas por indivíduos com deficiência visual, visando propor ambientes acadêmicos capazes de oferecer adequadas informações de orientação aos seus usuários e, com isso, promover qualidade de vida e inclusão social.

Sendo assim, este trabalho apresenta os resultados de uma pesquisa quali-quantitativa, do tipo exploratório-híbrido, que teve por finalidade sugerir o wayfinding como ferramenta de auxílio para a autonomia de pessoas com deficiência visual por meio de: (a) a identificação do comportamento de wayfinding desse grupo; (b) a identificação de aspectos físicos que auxiliam ou dificultam esse processo; (c) a proposta de diretrizes de um sistema de sinalização e 
Figura 1. Processo de

Wayfinding de Arthur

e Passini (2002).

Fonte: Cunha, 2019. de sugestão para um sistema informacional para os locais na Escola Politécnica da Universidade de Pernambuco (Poli/UPE), onde as pesquisas de campo foram executadas.

\section{WAYFINDING E A PESSOA COM DEFICIÊNCIA VISUAL}

Segundo Arthur e Passini (2002) o wayfinding é um processo construído a partir da dinâmica entre: (i) processos de tomada de decisão, (ii) de execução de tomadas de decisão e (iii) de processamentos da informação, como mostra a Figura 1. É um processo que sofre a interferência de fatores humanos e ambientais simultaneamente, sendo os primeiros a capacidade de percepção dos indivíduos e suas habilidades cognitivas; e os últimos, os elementos que contêm e fornecem informações sobre o ambiente durante a dinâmica do deslocamento.

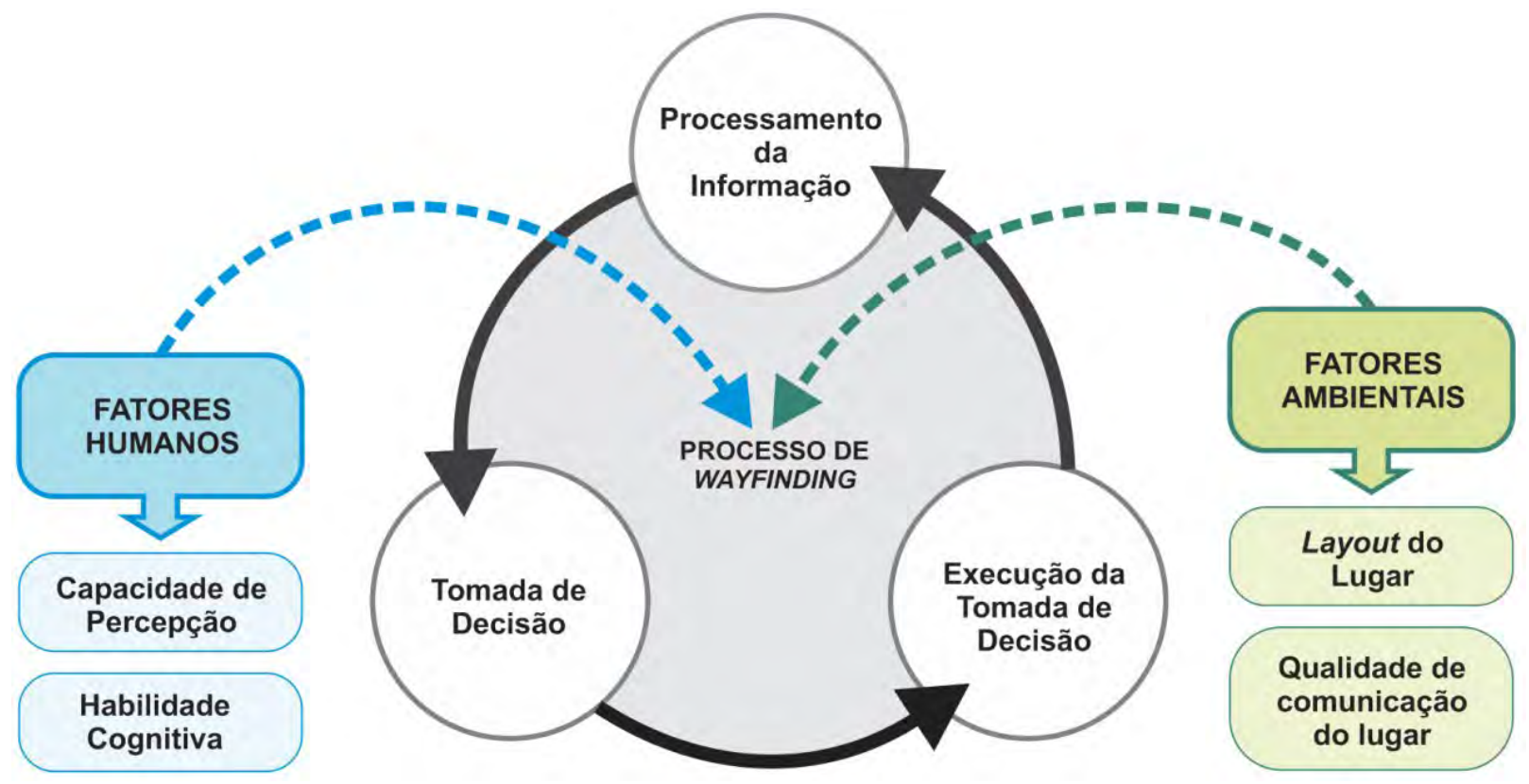

Sendo assim, afirma-se que os estudos de wayfinding auxiliam na avaliação da acessibilidade informacional em ambientes construídos, visto que, permitem apontar fragilidades quanto às pistas oferecidas pelo local durante o deslocamento dos indivíduos e como consequência, 
contribuem para o planejamento de espaços mais acessíveis e dinâmicos.

Ambientes desprovidos de informações adequadas podem levar a perigos inesperados, além do sentimento de impotência, frustração e exclusão. No entanto, o apoio encontrado em recursos visuais auxilia para que pessoas normovisuais tenham diversas opções de estratégias de navegação e que possam se reposicionar em seus deslocamentos com mais rapidez. Porém, a mesma situação pode não ocorrer com pessoas que têm deficiência visual, pois não possuem recursos visuais e meios táteis de informação com acesso facilitado.

Nesse caso, a desorientação pode ser muito mais séria e perigosa para esses indivíduos quando não conseguem basear suas estratégias de deslocamento em marcos referenciais ou visualizar obstáculos no caminho (ZIMRING; TEMPLER, 1983).

Zimring e Templer (1983) afirmam que as pessoas com deficiência visual elaboram predominantemente duas estratégias de orientação espacial para a realização de seus deslocamentos: (1) memorizar pontos de referência a cada rota e depois ligá-las sem que, necessariamente, exista uma relação entre elas; (2) memorizar todos os principais pontos de referência e ligá-los no intuito de formar um panorama do lugar por meio da elaboração de um mapa mental.

Também no sentido de buscar por um padrão no deslocamento de pessoas com deficiência visual, Passini e Proulx (1988) realizaram um experimento que buscou comparar o comportamento de wayfinding de pessoas com cegueira congênita e pessoas normovisuais, identificando algumas diferenças no que diz respeito às estratégias de navegação e semelhanças quanto à execução dos trajetos.

Segundo o experimento de Passini e Proulx (1988), quanto à execução dos trajetos, pessoas com deficiência possuem comportamento de wayfinding semelhante ao de pessoas normovisuais, a diferença reside na elaboração das estratégias de navegação, visto que, há a necessidade de um número maior de referências espaciais ao longo dos seus deslocamentos, assim como, é importante que essas referências estejam afastadas umas das outras, a uma distância confortável para a memorização e para promover a noção de distância.

Portanto, pode-se concluir a partir dos estudos de Zimring e Templer (1983) e Passini e Proulx (1988) que: (1) em deslocamentos no ambiente construído, pessoas normovisuais não se baseiam tanto na memória, pois encontram elementos visuais ao longo de seus trajetos que as mantêm informadas, o que não ocorre com pessoas cegas que necessitam se apoiar constantemente no recurso da memória para formar suas estratégias de navegação e seus mapas mentais; (2) as estratégias de navegação elaboradas por pessoas com deficiência visual, independente da forma de memorização adotada, necessitam de uma dimensão e posicionamento estratégicos de referências espaciais que possam suprir informações sobre seus percursos e que forneçam opções para tomadas de decisão. 


\section{A SINALIZAÇÃO COMO REFERÊNCIA ESPACIAL NO COMPORTAMENTO DE WAYFINDING}

Referências espaciais são, portanto, fatores ambientais que atuam no processo de wayfinding, podendo ser categorizadas em: (i) Layout do lugar, quando dizem respeito à configuração espacial do ambiente; (ii) qualidade da comunicação do lugar, sendo subdividido em Expressões Arquitetônicas e Expressões Gráficas. Destas, as primeiras são formadas por elementos pontuais que constituem a arquitetura do lugar, e as últimas são os elementos gráficos de sinalização (ARTHUR; PASSINI, 2002).

Mollerup (2013) corrobora com o conceito de Arthur e Passini (2002) sobre fatores ambientais que influenciam o wayfinding, considerando tais fatores como toda a identidade intrínseca ao lugar e que transmite alguma informação sobre o ambiente para o indivíduo ou um elemento colocado no espaço unicamente com o objetivo de informar algo específico, sendo denominado, neste caso, de sinalização.

As classificações quanto aos tipos de sinalização mudam de designer para designer, mas, no entanto, podem se sobrepor a algumas e complementar outras (CALORI; VANDEN-EYNDEN, 2015). Quanto ao ambiente construído, podem ser classificadas basicamente pelas suas atribuições de regulação, de indicar perigos, de orientar quanto ao deslocamento do indivíduo ou de instruir sobre determinados lugares (CUNHA, 2019).

As sinalizações de wayfinding, que têm como objetivo orientar o deslocamento no ambiente construído (CALOR; VANDENEYNDEN, 2015), devem possuir as características de informação (orientação), identificação e direção (CARPMAN; GRANT, 2002; ARTHUR; PASSINI, 2002).

Estas características são atribuídas a elementos de sinalização, em função do comportamento de wayfinding, que se busca atender, como mostra a Figura 2. Mapas são utilizados, predominantemente, como elementos de orientação (neste contexto) durante a etapa de planejamento (estratégias de navegação) e placas de direção e de 
identificação como elementos de sinalização

Figura 2. Sinalização

utilizados durante a execução do desloca-

e Comportamento

mento e de identificação do destino final

de wayfinding. Fonte:

respectivamente (ARTHUR; PASSINI, 2002).

Cunha, 2019.

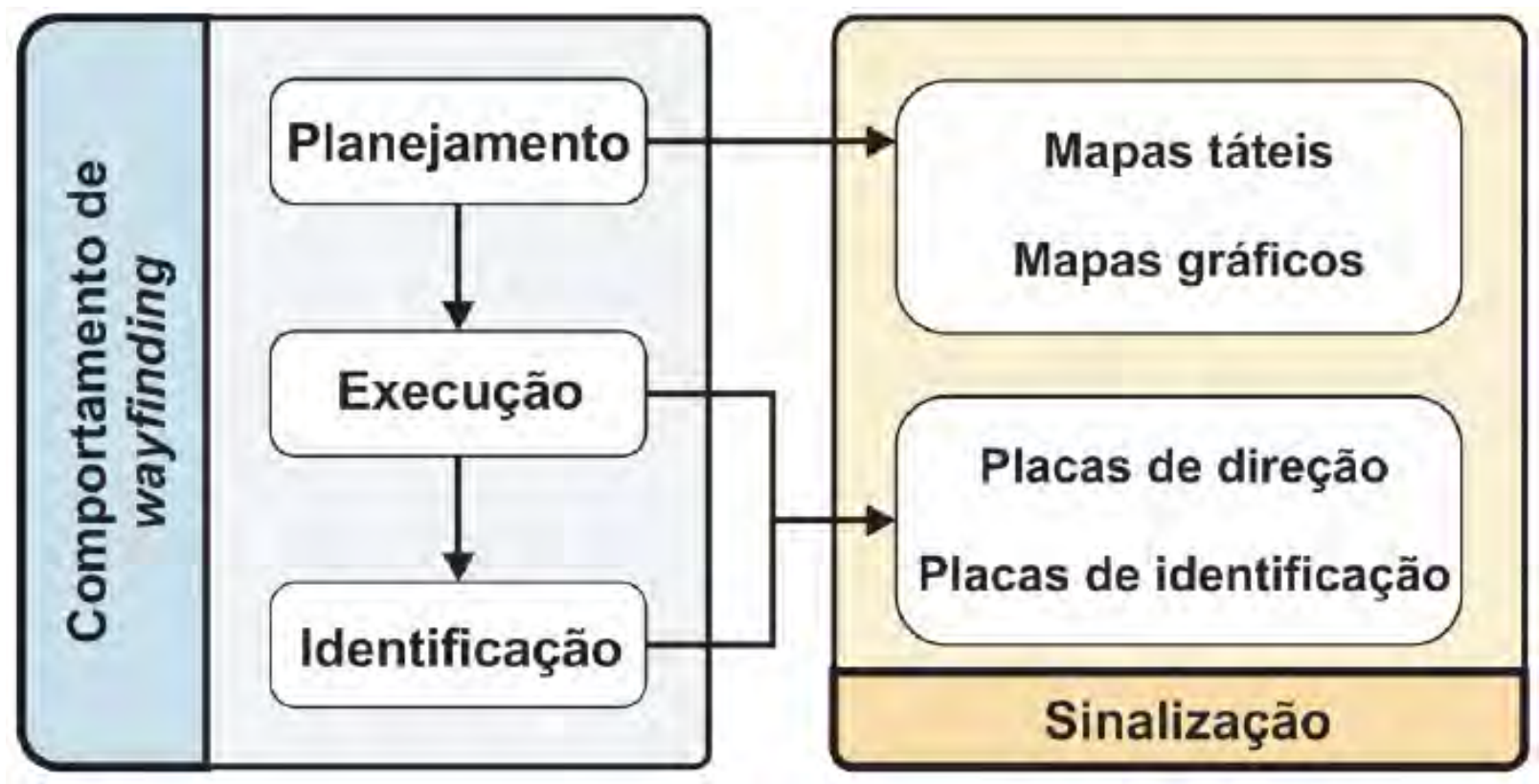

Destarte, pode-se afirmar que a sinalização

de wayfinding, além de assumir o papel de referência espacial que possui maior rapidez na transmissão da mensagem até o receptor no ambiente construído (MOLLERUP, 2013), também assume predominantemente três principais características em função do tipo de comportamento de wayfinding adotado. Ou seja, é de fundamental importância que os elementos de sinalização de wayfinding estejam bem dimensionados no ambiente, a fim de proporcionar informações corretas e seguras aos usuários. 
Figura 3. Desenho

esquemático do

local de pesquisa.

Fonte: Cunha, 2019.

\section{ESTUDO DE CASO}

A pesquisa foi dividida em duas etapas. A primeira etapa teve como objetivo principal identificar como ocorre o comportamento de wayfinding de pessoas com deficiência visual, e quais são os aspectos físicos que interferem nesse processo. Foi realizada em rotas pré-estabelecidas que interligam os acessos principais dos blocos A, B e K/I, e denominadas (pela pesquisa) de $\operatorname{rotas} A, B, C, D$ e E na Escola Politécnica da Universidade de Pernambuco (Poli/UPE).

Nessa primeira etapa, a amostra foi formada por participantes vinculados à Universidade Federal de Pernambuco. Dois participantes com baixa visão e um com cegueira adquirida. A seleção da quantidade de participantes se deu por amostragem não probabilística e de participação voluntária: por conveniência e do tipo "Bola de Neve" (snowball sample).

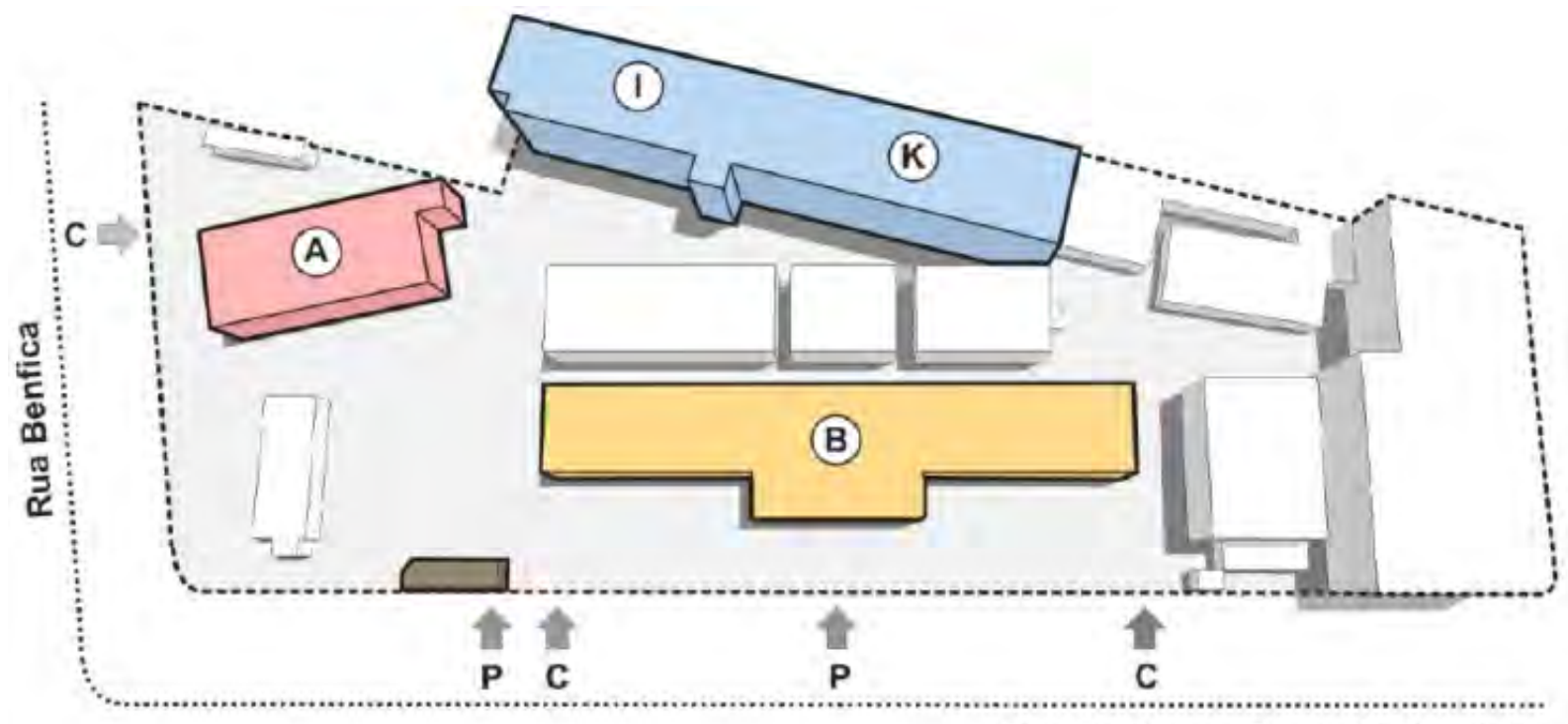

Rua Professor Benedito Monteiro

\section{Legenda}

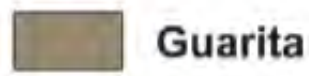

a Acesso para carros

P Acesso para pedestres
(A) Bloco A
(B) Bloco B
(K) (I) Bloco K/I 
A segunda etapa teve como objetivo principal coletar dados por meio da validação de um sistema informacional vertical e em protótipos no bloco K/I da instituição, com finalidade de fornecer embasamento para a elaboração de sugestões de uma sinalização para o local. Para isso, a validação dos protótipos buscou compreender se a sinalização proposta atendia ao processo de wayfinding de pessoas com deficiência visual no local estudado.

Na segunda etapa, a amostra foi formada por dez pessoas com deficiência visual (cegueira e baixa-visão): três participantes com baixa-visão, três participantes com cegueira congênita e quatro participantes com cegueira adquirida.

\section{PROCEDIMENTOS METODOLÓGICOS: TIPO DE PESQUISA}

Baseando-se nos seus objetivos (geral e específicos), afirma-se que esta pesquisa é do tipo exploratório-híbrido. Segundo Gil (2002), uma pesquisa exploratória tem como objetivo "proporcionar maior familiaridade com o problema, com vistas (sic) a torná-lo mais explícito ou a construir hipóteses". Outra característica da pesquisa exploratória, e intrínseca a esta pesquisa em particular, é que versa sobre assunto pouco explorado e sobre o qual não se acumula ainda uma produção teórica nacional significativa. 
Quadro 1. Tipo de

Pesquisa. Fonte:

Cunha, 2019.
Baseando-se nos seus procedimentos técnicos utilizados, a pesquisa é híbrida, pois contempla três tipos de procedimentos metodológicos: pesquisa bibliográfica, estudo de campo e, com base neste último, a pesquisa-ação.

\section{Tipo de Pesquisa: Exploratório-Híbrido}

Segundo os objetivos

Exploratório
Segundo os procedimentos técnicos

Híbrida

Estudo de campo Pesquisa-ação
Pesquisa

bibliográfica

Trata-se de uma pesquisa bibliográfica, pois tem como objetivo inicial fundamentar o problema de pesquisa por meio do uso de material sobre a área de estudo, produzido por diversos autores.

Do tipo estudo-de-campo, pois realiza a pesquisa no locus do fenômeno que se pretende estudar e lança mão de técnicas de coleta de dados, entrevistas aos envolvidos, formulários de observação sistemática, como é conceituada segundo Gil (2002).

E, por fim, trata-se de uma pesquisa-ação por conectar as problemáticas citadas às possíveis soluções baseadas no processo de wayfinding.

\section{PROCEDIMENTOS METODOLÓGICOS: PRIMEIRA ETAPA}

Nessa primeira etapa, os procedimentos metodológicos foram realizados em três fases distintas como mostra a Figura 4. A primeira fase trata de uma revisão sistemática de literatura referente à fundamentação teórica, métodos e a sistemas de sinalização; a segunda fase trata do reconhecimento do local por meio do levantamento arquitetônico das áreas envolvidas na pesquisa, do 
método de mapeamento do comportamento centrado no lugar e de uma contagem de pessoas; por fim, a terceira fase foi composta pela elaboração das rotas a serem percorridas e pela estruturação adaptada do método do Walkthrough para esta primeira etapa da pesquisa.

\section{PROCEDIMENTOS METODOLÓGICOS} Primeira Etapa

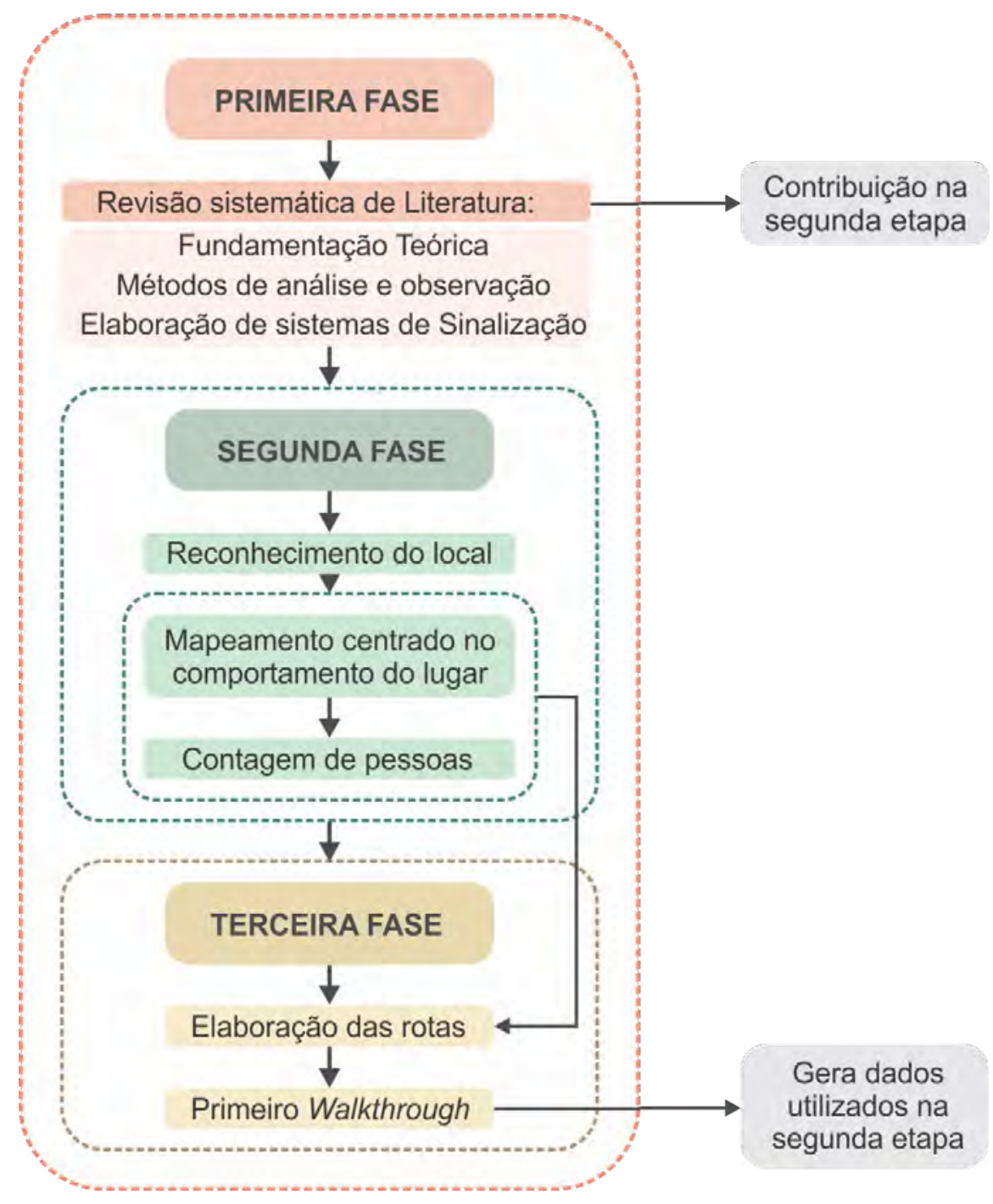

Figura 4. Esquema dos Procedimentos Metodológicos da Primeira Etapa. Fonte: Autoras 
Figura 5. Esquema

da coleta de dados

para a segunda etapa.

Fonte: Autoras
PROCEDIMENTOS

METODOLÓGICOS:

SEGUNDA ETAPA

Nessa segunda etapa, os procedimentos metodológicos foram adotados com a finalidade de (i) elaborar diretrizes para um sistema de sinalização nas rotas propostas

(E1) e (ii) elaborar protótipos de sinalização para o bloco K/I (E2) para a validação de uma sugestão de sinalização vertical a ser proposta para o local. Sendo assim, parte dessa etapa passa a depender de dados obtidos após a execução dos procedimentos metodológicos da primeira etapa da pesquisa.

Para a realização de E1 e E2 a pesquisa baseou-se na metodologia de Joan Costa (2007), que sugere etapas para a elaboração de sistemas de sinalização: (1) coleta de dados; (2) concepção do sistema; (3) sistema de sinais ou código base; (4) design gráfico; (5) fichas técnicas para a produção; (6) supervisão e implementação.

PROCEDIMENTOS METODOLÓGICOS

Segunda Etapa: Coleta de dados

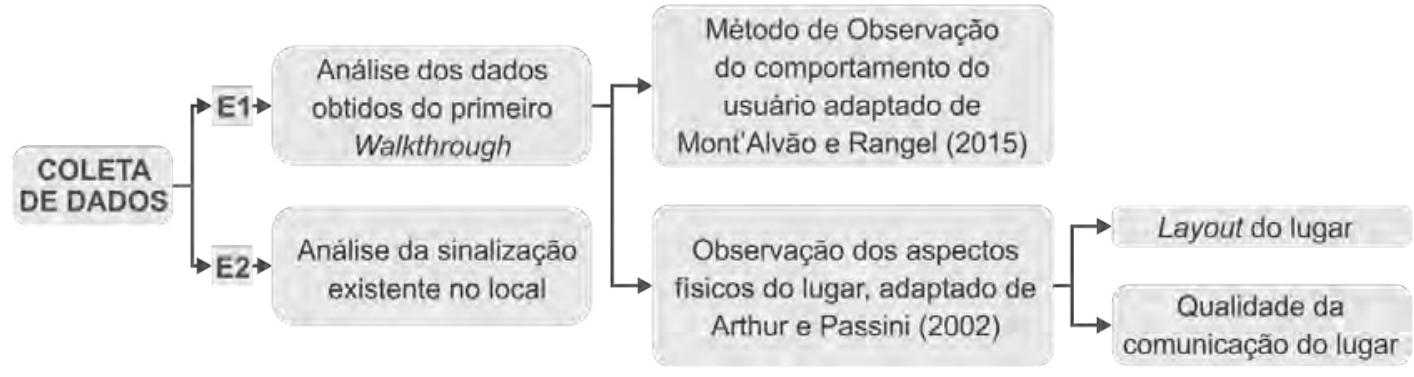

Quanto à coleta de dados, foram propostos métodos e procedimentos metodológicos distintos para E1 e E2, como mostra a Figura 5. A coleta de dados para E1 se deu por meio das análises dos dados obtidos durante a execução do primeiro Walkthrough, e para E2, por meio da análise da sinalização existente no local. As etapas de: (2) concepção 
do sistema e (3) sistemas de sinais ou código base têm como objetivo elaborar uma forma de representação dos elementos de sinalização em códigos para que possam ser visualizados em mapas.

As demais etapas atendem exclusivamente a E2. Tratam do desenvolvimento do design dos protótipos, da elaboração das fichas técnicas utilizadas para o desenvolvimento e avaliação dos protótipos; e, por fim, da etapa de supervisão e implementação trata dos materiais dos elementos de sinalização e da estruturação do segundo walkthrough, também adaptado, que finaliza os procedimentos metodológicos desta etapa.

\section{ELABORAÇÃO DAS ROTAS}

Para a definição das rotas, inicialmente foi realizado o experimento do mapeamento centrado no lugar, com intuito de reconhecer como o ambiente em questão era utilizado. Com isso, foram definidos cinco pontos de observação para a realização do instrumento. Esses pontos foram escolhidos levando em consideração as entradas e saídas das edificações, assim como, foram levados em consideração os acessos de maior interesse comum dentro dos edifícios. Quanto aos horários, foram selecionados aqueles com maior movimentação de pessoas, como os horários entre aulas, turnos, início ou final das aulas, evitando finais de semana, férias e feriados.

Em seguida, foi realizado o experimento denominado pela pesquisa como contagem de pessoas, com o intuito de contar, com um medidor, a quantidade de pessoas que circulavam nos cinco pontos observados pelo método de mapeamento centrado no lugar. $O$ intuito da realização desse instrumento foi promover uma comparação entre os números de pessoas circulando e o tipo de uso predominante encontrado nos referidos pontos, para então realizar um cruzamento de dados e poder reconhecer, por fim, quais pontos seriam inseridos nas rotas em função da permanência no local e intensidade de fluxo, como mostra o Quadro 2. 
Quadro 2.

Cruzamento de mapa

comportamental e

contagem. Fonte:

Cunha, 2019.

\section{Classificação da quantidade do fluxo de pessoas}

Baixo Fluxo

D

Médio Fluxo

$\mathbf{F}$

Alto Fluxo

G

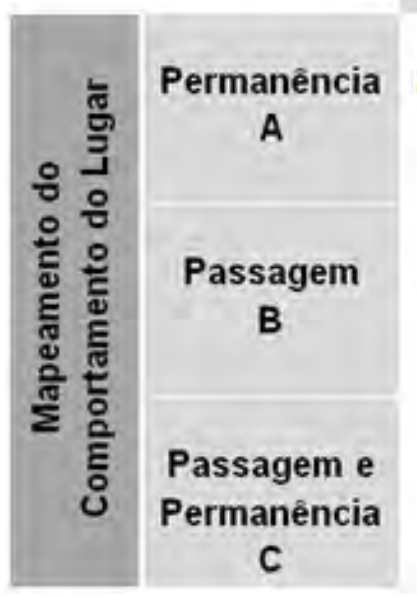

\section{Relevante \\ AF}

Relevante

$\mathrm{AD}$

Relevante
BD
Relevante
BF

Relevante

CD
Relevante
CF

AG

\author{
Muito Relevante \\ BG
}

Muito Relevante

CG

Assim, foram definidas as cinco rotas dentro da instituição onde os participantes realizariam os experimentos da primeira etapa da pesquisa denominadas de: Rota $A$, Rota B, Rota C, Rota D e Rota E - sendo esta, subdividida em Rota E1 e Rota E2.

\section{PRIMEIRO WALKTHROUGH}

O objetivo do primeiro walkthrough é sugerir um sistema de sinalização para as rotas percorridas, por meio de (i) dados coletados da observação do comportamento dos participantes nas rotas e (ii) por meio de dados que identificassem quais foram os aspectos físicos que estavam presentes nessas rotas e que influenciaram o processo de wayfinding dessas pessoas.

Para a realização desse experimento, foi elaborado um mapa esquemático (Figura 6) com indicações dos locais onde os comportamentos foram observados. Para a análise do comportamento dos participantes, foi levado 
em consideração os seguintes aspectos: como os partici-

Figura 6. Locais

pantes elaboraram suas estratégias de navegação; como de observação do executaram essas estratégias; e se, ao chegarem no final comportamento. do percurso, reconheciam o lugar onde estavam como $o$ Fonte: Cunha, 2019. destino final do trajeto previamente elaborado.

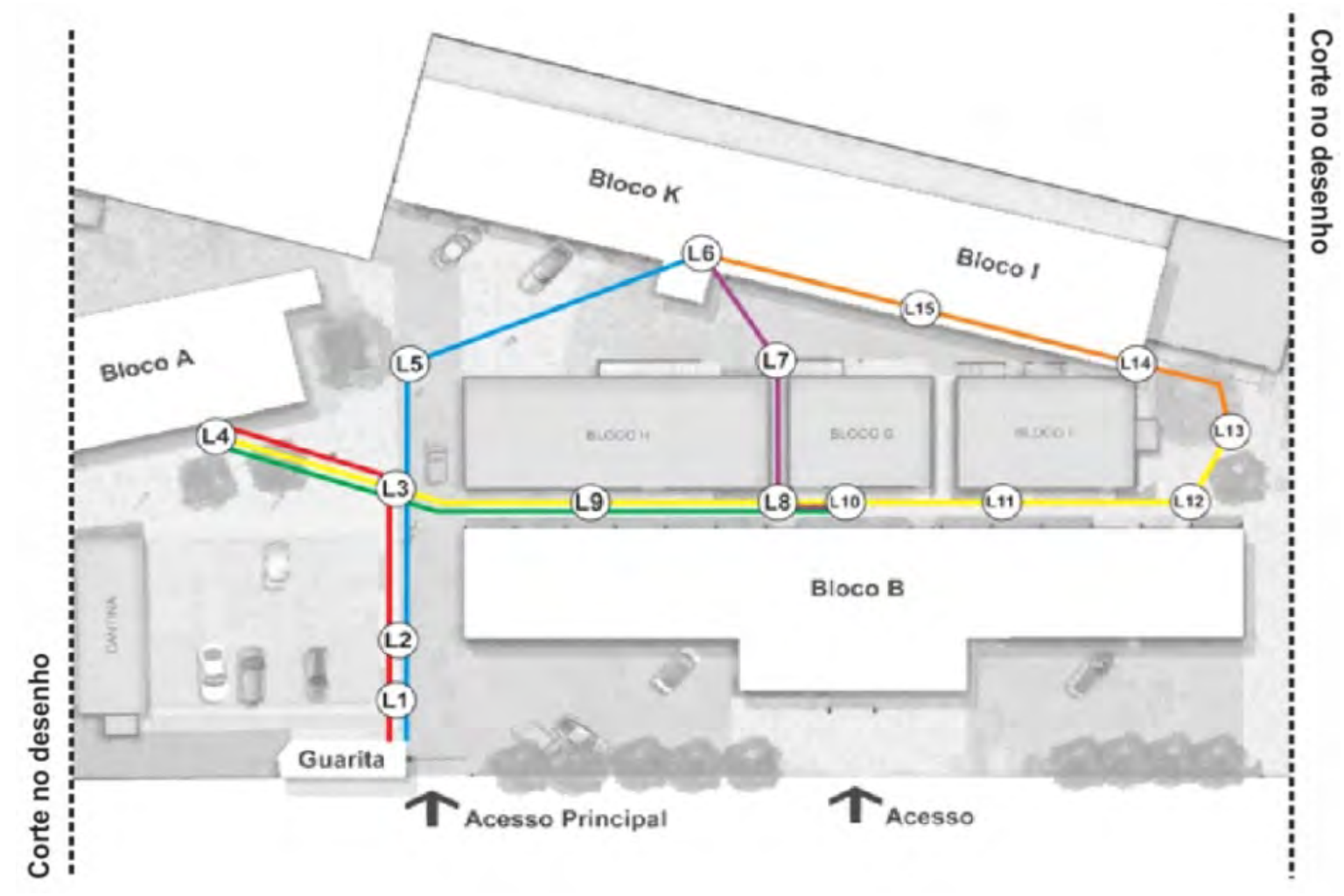

\section{PROTÓTIPOS DE SINALIZAÇÃO}

Foram confeccionados dois mapas táteis, um mapa gráfico, oito placas verticais, sendo uma do tipo diretório, para a realização do segundo Walkthrough na segunda etapa da pesquisa:

Além dessas oito placas, foram confeccionadas mais quatro que foram utilizadas quando os participantes optavam fazer o trajeto pela escada e não pelo elevador: 


\section{Figura 7.}

Posicionamento dos

protótipos em planta.

Fonte: Cunha, 2019.
A. a nona placa (I) foi colocada na escada do pavimento térreo;

B. a décima placa $(\mathrm{J})$ foi colocada na escada do primeiro pavimento;

C. a décima primeira placa $(K)$ foi colocada na escada do segundo pavimento;

D. a décima segunda placa (L) foi colocada no elevador do primeiro andar.

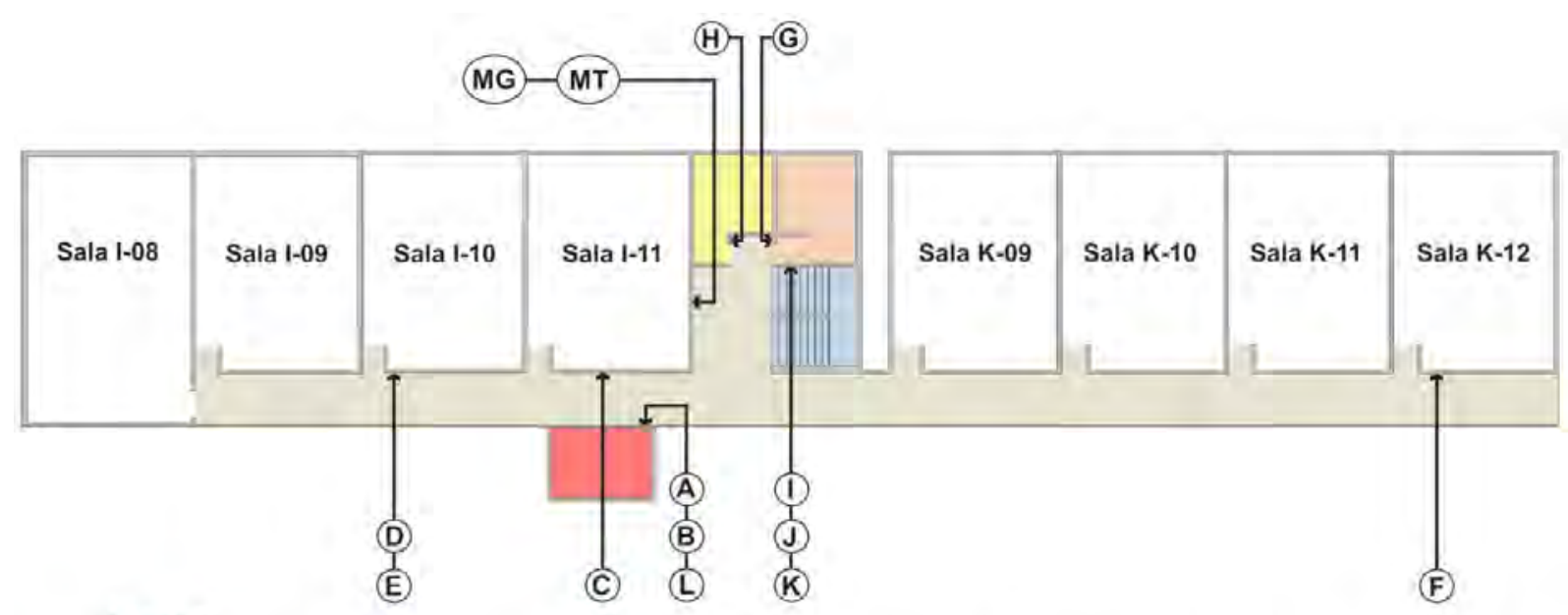

Legenda

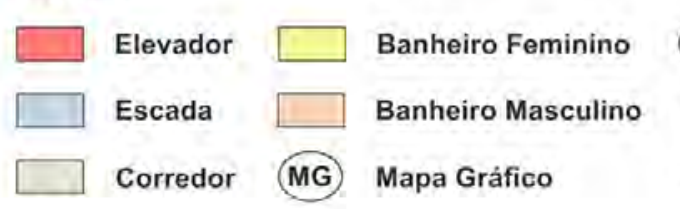

$\begin{array}{lllll}\text { MT) Mapa Tátil } & \text { (C) Placa C } & \text { (F) Placa F } & \text { (1) Placa I } \\ \begin{array}{llll}\text { (A) Placa A } & \text { (D) Placa D } & \text { (G) Placa G } & \text { (D) Placa J } \\ \text { (B) Placa B } & \text { (E) Placa E } & \text { (H) Placa H } & \text { (L) Placa K }\end{array}\end{array}$

Quanto aos mapas táteis, o primeiro refere-se à Rota $A$ e à Rota $B$. Foi sugerido no início e no final da pesquisa de campo apenas para o participante reconhecer o caminho (que iniciava na guarita da instituição), com destino até o Bloco $\mathbf{K} / \mathbf{I}$ e ao Bloco $\mathbf{A}$, assim como desses dois blocos até a guarita novamente. 

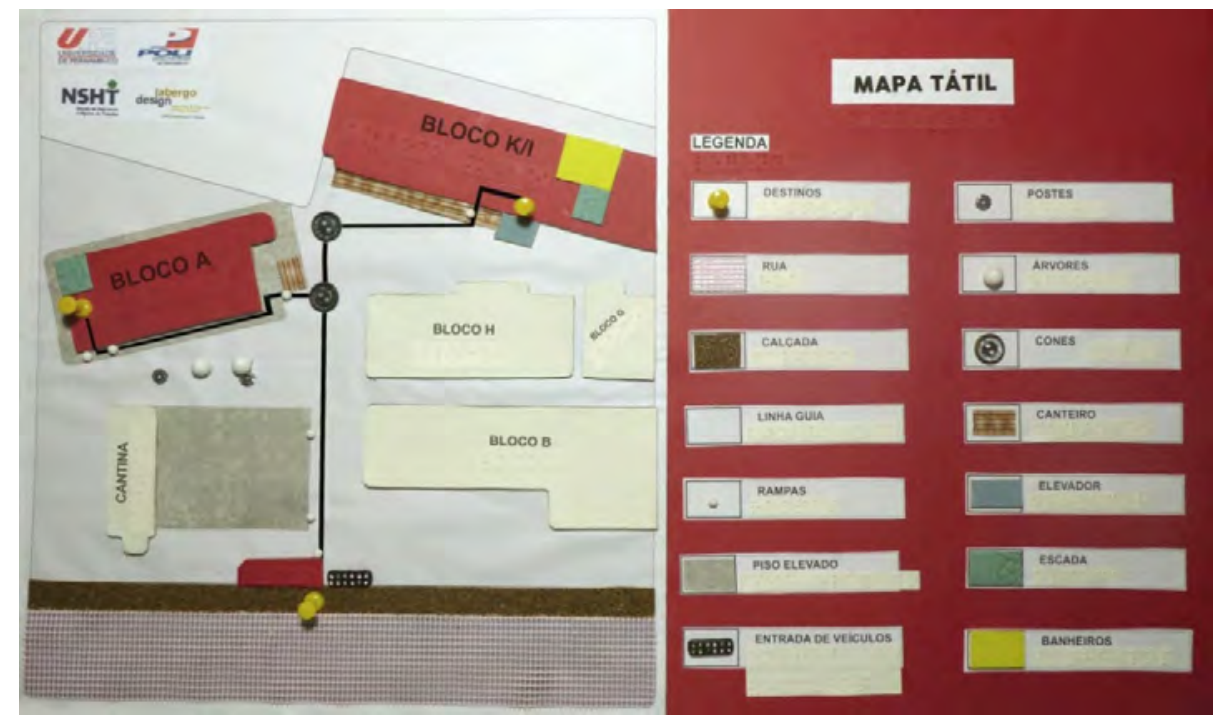

Figura 8. Primeiro mapa tátil. Fonte: Acervo das autoras.

Figura 9. Segundo mapa tátil. Fonte: Acervo das autoras.

O segundo mapa tátil refere-se ao mapa do segundo pavimento do Bloco K/I. Nele foram apresentados: os banheiros (feminino e masculino); escada; bebedouro (pois pode ser utilizado como referência de navegação); mapa tátil; peitoril; parede de tijolos de vidro (que também são utilizados como pontos de referência); elevador; portas; posicionamento das placas de identificação das salas de aula.

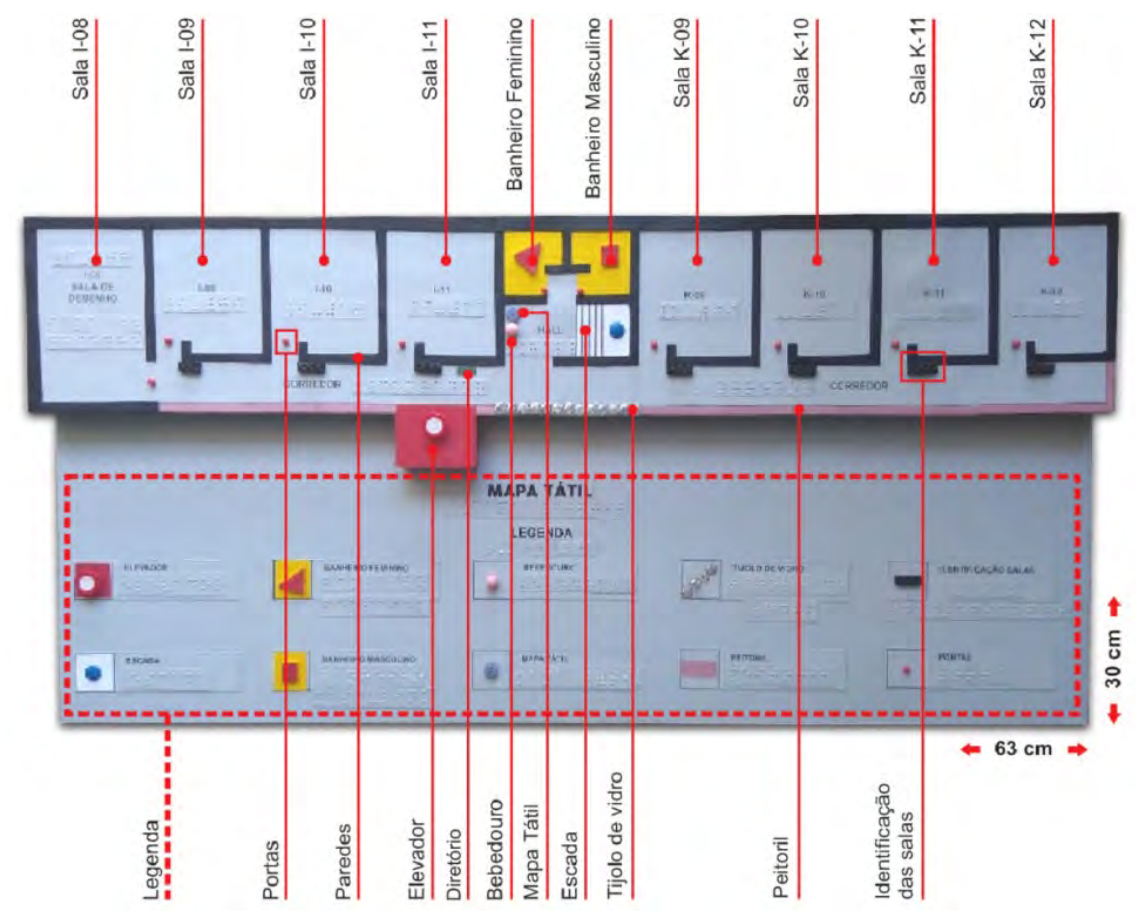


Figura 10. Esquema

Placa C. Fonte:

Cunha, 2019.

Figura 11. Placas A

(1), $B(2)$ e $L(3)$. Fonte:

Cunha, 2019.
A placa $\mathrm{C}$ foi posicionada em frente ao elevador, com texto impresso e em Braille.. Ela informa o número do pavimento, os nomes dos blocos, direção aos sanitários, direção da escada e direção das salas: à esquerda as salas do bloco I e à direita as salas do bloco $\mathrm{K}$.

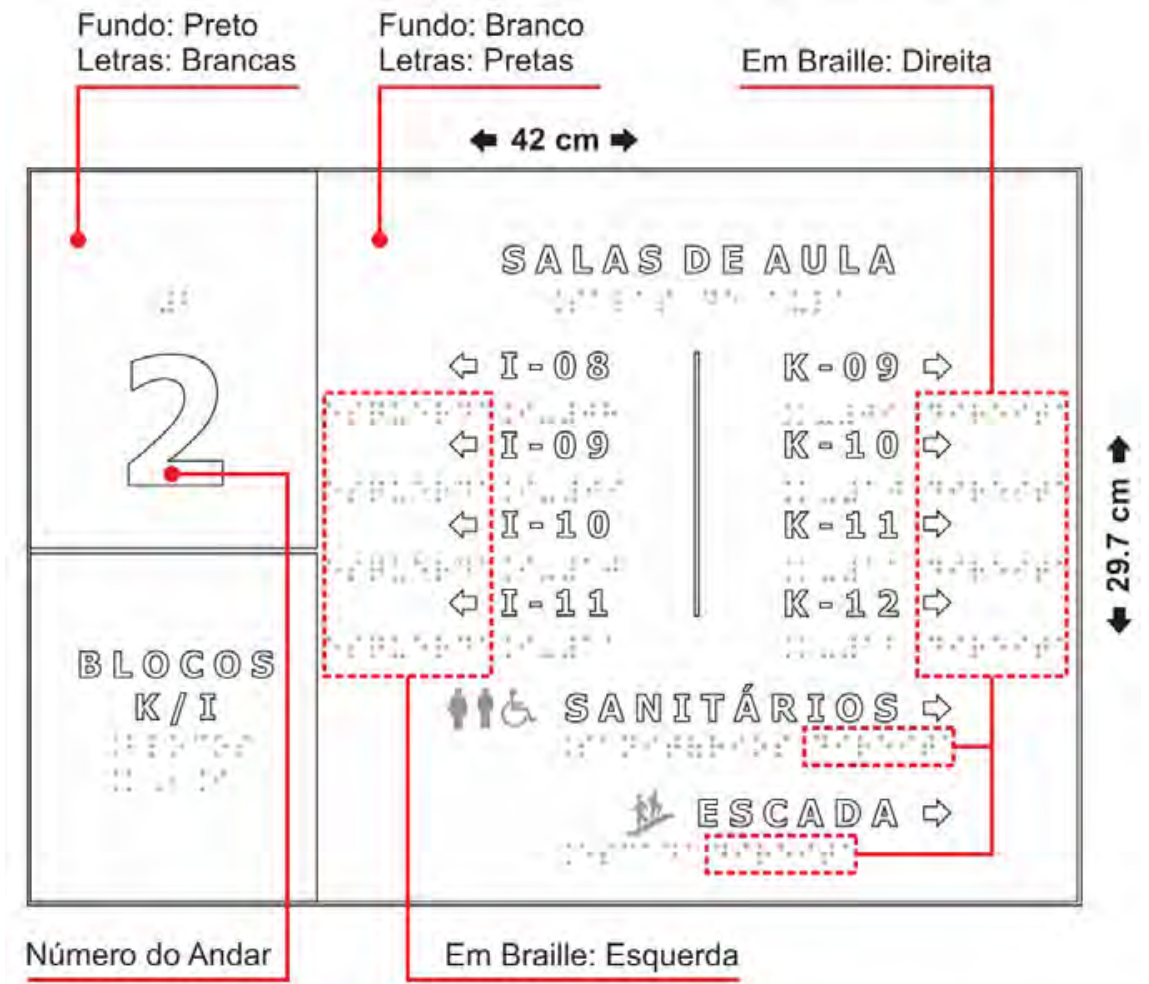

As placas A, B e $L$ apresentam textos impressos e em Braille. As três têm $21 \mathrm{~cm}$ de largura, $14,85 \mathrm{~cm}$ de comprimento e estão posicionadas a 1,20 $\mathrm{m}$ do piso. Foram confeccionadas com fundo branco e tipos pretos.

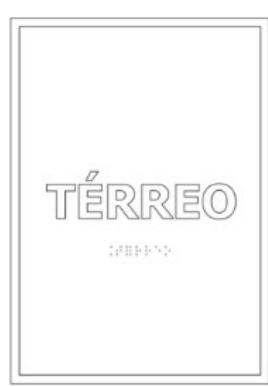

1

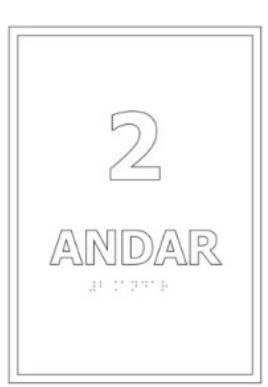

2

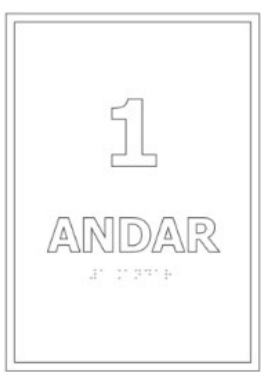

3 
As placas D, E e F têm 29,7 cm de comprimento e $21 \mathrm{~cm}$ de largura. Apresentam textos impressos e em Braille. Foram confeccionadas com fundo branco e tipos pretos. As placas $D$ e $F$ foram instaladas a 1,60 $\mathrm{m}$ de distância do piso e a placa $\mathrm{E}$ foi instalada a 1,20 m de distância do piso.

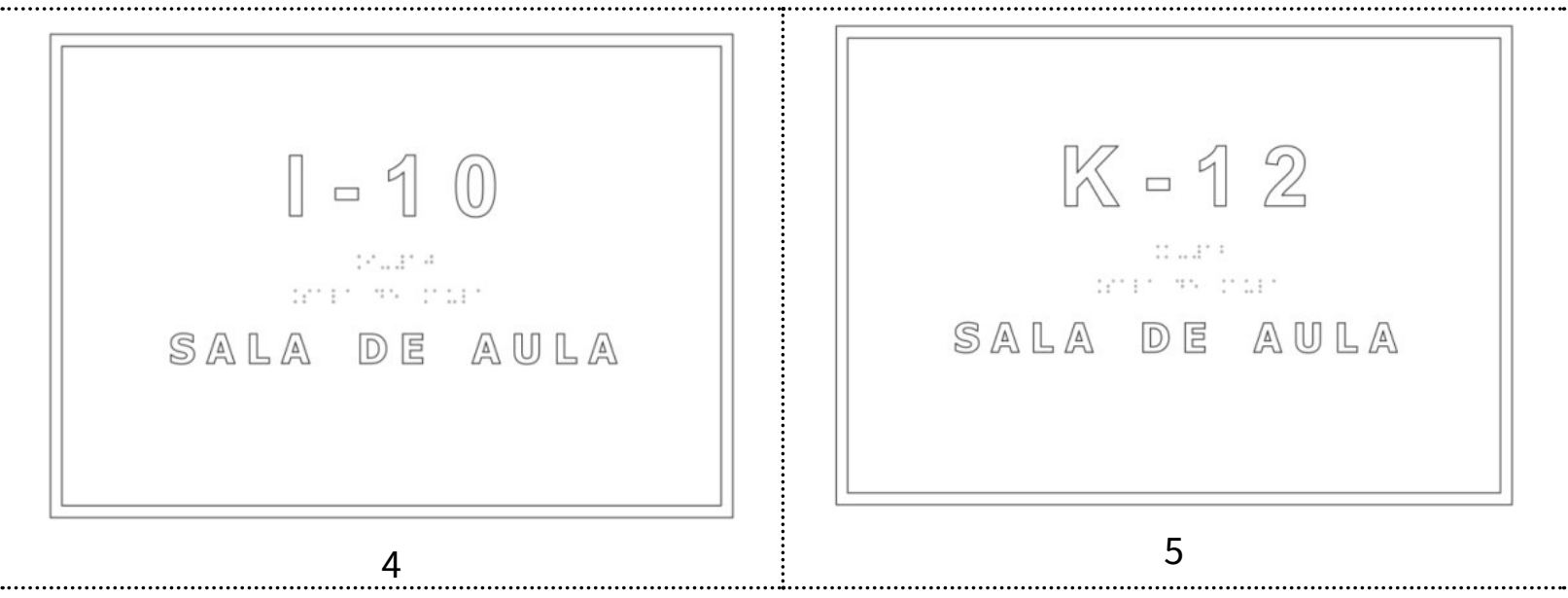

As placas $\mathrm{G}$ e H têm 14,85 cm de comprimento e $21 \mathrm{~cm}$ de largura. Apresentam textos impressos e em Braille. Foram confeccionadas com fundo branco e tipos pretos. Foram instaladas a 1,20 m de distância do piso.

Nas Figuras 13 e 14 estão representadas as placas em desenhos esquemáticos, com objetivo de expor a altura em que cada placa foi posicionada e a relação dessas alturas com a escala humana. No lado esquerdo de cada desenho esquemático está uma régua - para comparação das alturas - escalonada em 10 a cada $10 \mathrm{~cm}$.

Figura 13.

Posicionamento das placas verticais. Fonte: Cunha, 2019

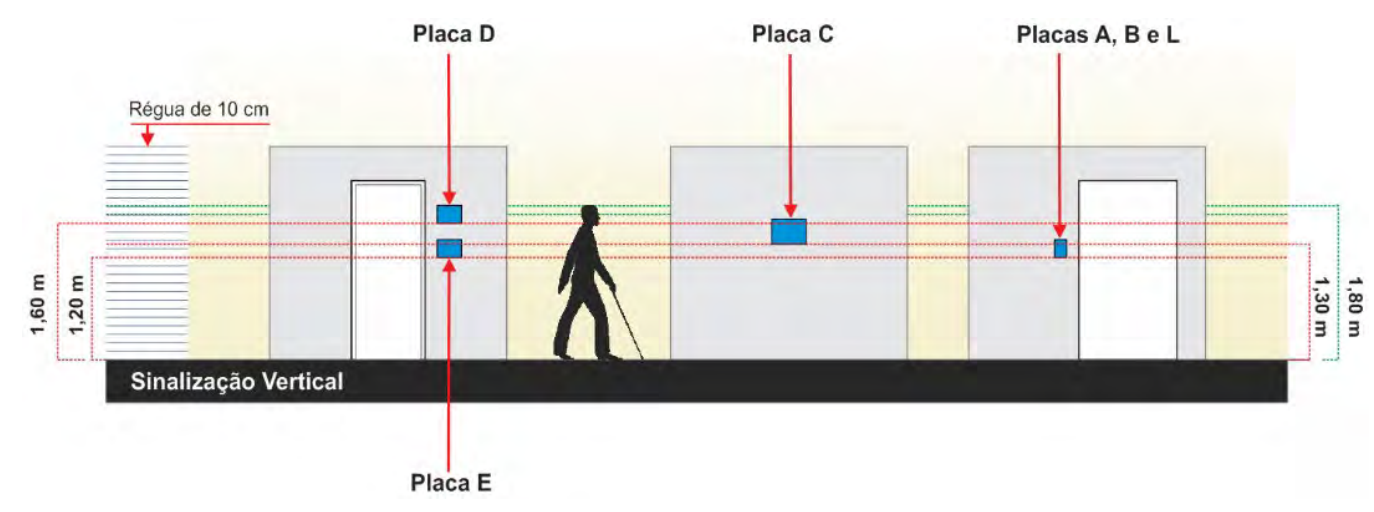




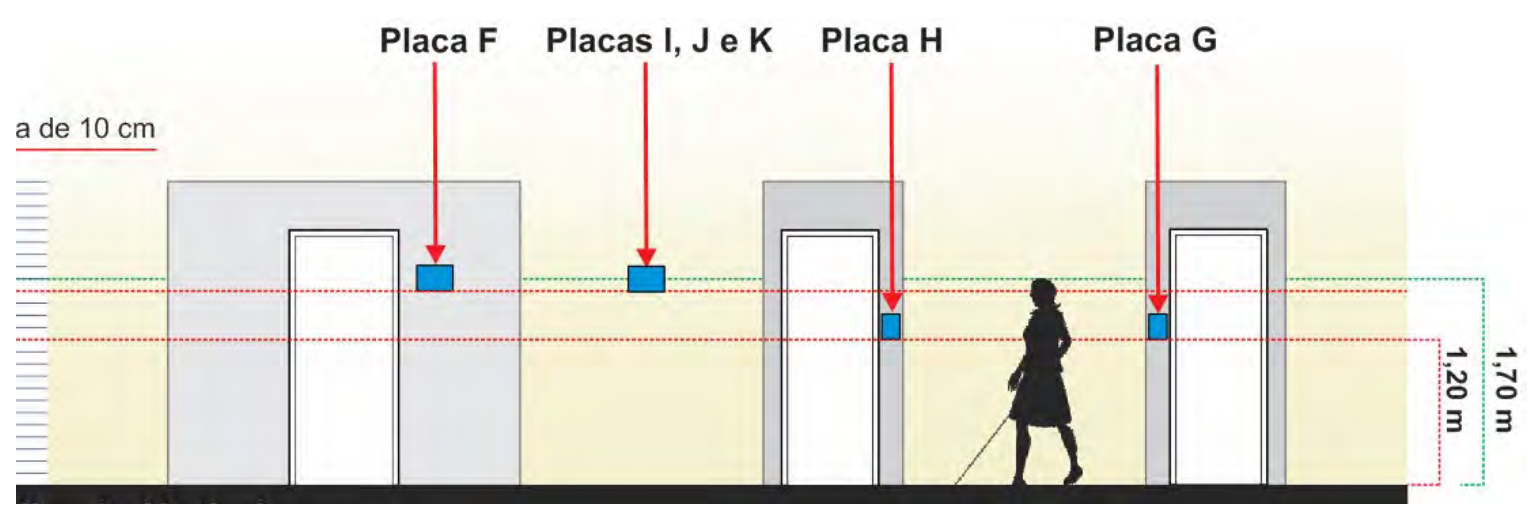

\section{SEGUNDO WALKTHROUGH}

O segundo walkthrough difere do primeiro, no que diz respeito aos objetivos a serem alcançados. Lembrando que, no primeiro, não havia meta a ser atingida durante o percurso, o objetivo era apenas de partida e chegada. No segundo, foram criados objetivos por ser um espaço menor e com uso mais diversificado. Com isso, foi pedido aos participantes que realizassem 13 objetivos, que foram:

Figura 14.

Posicionamento

das placas verticais.

Fonte: Cunha, 2019
A. Fizessem uma leitura do Mapa Tátil;

B. Realizassem o percurso da Rota B (Guarita até o elevador do Bloco K/l);

C. Utilizassem o elevador e subissem até o segundo pavimento;

D. Lessem o diretório em frente ao elevador;

E. Fizessem o deslocamento até a sala I-10;

F. Fizessem o deslocamento até a sala K-12;

G. Encontrassem os banheiros;

H. Encontrassem a escada

I. Descessem até o pavimento térreo utilizando o elevador;

J. Caminhassem do elevador até a guarita (Trajeto inverso da Rota B);

K. Caminhassem da guarita até a calçada do Bloco A;

L. Fossem até a porta principal do Bloco A;

M. Caminhassem de volta do Bloco $A$ até a guarita. 


\section{APRESENTAÇÃO DOS DADOS E RESULTADOS: PRIMEIRA ETAPA.}

O objetivo da primeira etapa foi identificar o comportamento de wayfinding dos participantes e levantar quais aspectos físicos - contidos no local de estudo - afetaram o deslocamento pelas rotas propostas.

Para avaliar o comportamento de wayfinding, foram observados três características durante a realização dos trajetos pelos participantes: (1) estratégias de navegação; (2) execução das rotas; (3) identificação do destino final.

Para avaliar os aspectos físicos, estes foram classificados segundo a categorização proposta por Arthur e Passini (2002): Layout do Lugar e Expressões Gráficas. Em que o layout do lugar diz respeito às configurações espaciais do ambiente e as expressões gráficas são mais direcionadas às sinalizações com finalidades mais objetivas e pontuais.

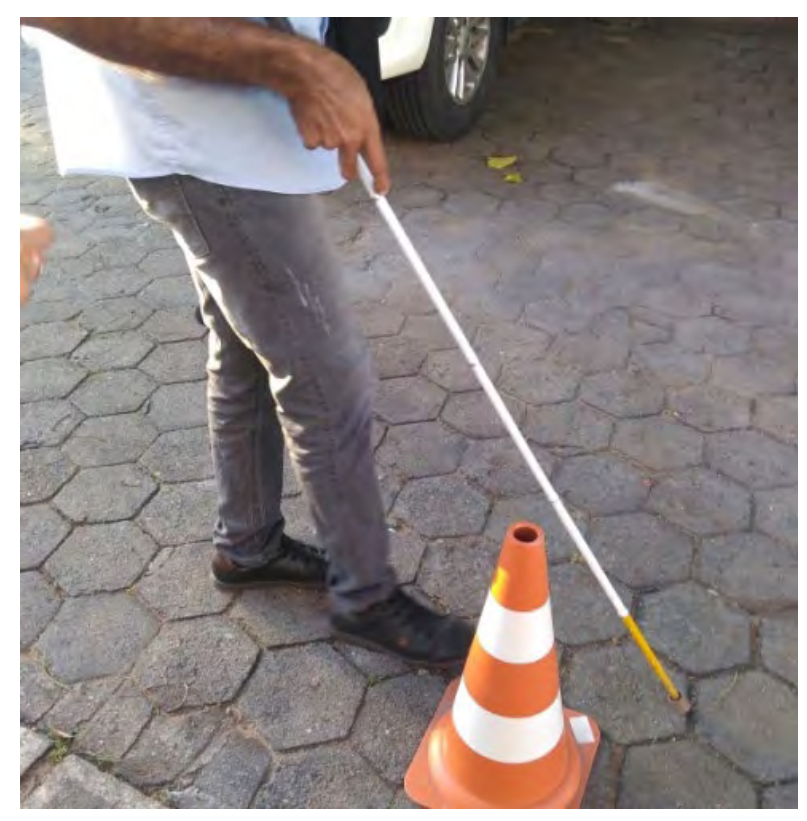


Sendo assim, quanto ao comportamento de wayfinding, foi observado que em relação às estratégias de navegação: a) os participantes adotaram a estratégia do tipo "seguir rotas", em que os sujeitos recebem as informações antes de executar o trajeto e guardam mentalmente ou anotam em meio físico para poderem ser consultadas durante a execução da rota; b) todos verbalizaram ter compreendido as informações fornecidas em mapas, relataram quais seriam suas estratégias de navegação e tiraram dúvidas antes da realização do experimento.

No que diz respeito à execução das rotas, a falta de referências no local que dialogassem com as referências espaciais memorizadas fez com que eles se perdessem diversas vezes. Portanto, pode-se concluir que, na fase do planejamento do trajeto os participantes não apresentaram dificuldades; no entanto, na fase de execução do trajeto as dificuldades surgiram.

Na terceira característica observada, a de identificação dos destinos finais, percebeu-se que após os voluntários terem apresentado muita dificuldade em orientação espacial durante a execução das rotas, demonstrando ou verbalizando sentir desconforto, desorientação e, muitas vezes, receio em seguir o trajeto, não conseguiam encontrar os destinos que haviam sido planejados durante o momento de elaboração das estratégias de navegação.

Diferente do comportamento de wayfinding - que fora observado ao longo da realização de todo trajeto -, os aspectos físicos que interferem no processo de wayfinding foram observados em lugares específicos nas rotas e onde os participantes apresentaram mais dificuldade, característica que trouxe para a pesquisa dados mais diretos e mais objetivos. Assim, os aspectos físicos mais apontados pelos participantes como sendo obstáculos ao wayfinding foram: circulações mal definidas; ausência de sinalização; acessos (entradas e saídas) sem identificação clara; e ausência de referências espaciais.

Observou-se que $32 \%$ de dificuldades nesses lugares se deram em função de circulações mal definidas; $32 \%$ se deram pela ausência de identidade do lugar; $21 \%$ foram os acessos mal sinalizados às edificações e 15\% pela ausência de referências espaciais, como mostra a Figura 16. 


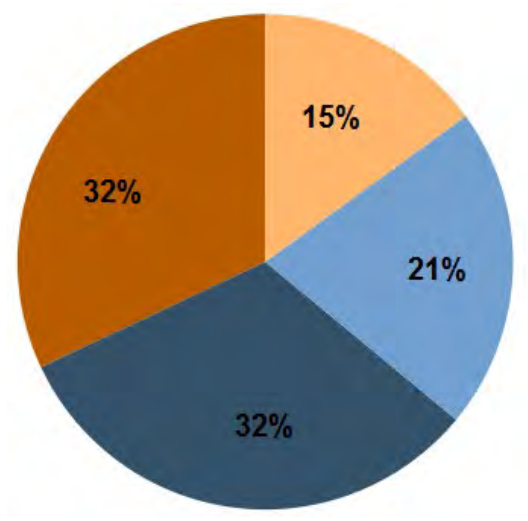

Layout do Lugar

Expressões Gráficas

$\square$

- Circulações mal definidas

- Ausência de sinalização

E Acessos mal sinalizados às edificações

Ausência de referências espaciais

Portanto, pode-se afirmar que $\mathbf{5 3} \%$ das dificuldades encontradas se referem aos aspectos de expressões gráficas e arquitetônicas e os $\mathbf{4 7} \%$ restantes se referem ao Layout do lugar. 0 que implica dizer que metade dos aspectos físicos encontrados que interferiram no comportamento de wayfinding dos participantes ocorreu pela ausência de elementos de sinalização (arquitetônicos e gráficos), e a outra metade por questões mal resolvidas quanto à identidade, organização e ligação entre as unidades espaciais e zonas de destinação do lugar.

\section{APRESENTAÇÃO DOS DADOS E RESULTADOS: SEGUNDA ETAPA}

O objetivo desta segunda etapa foi: a) observar o comportamento de wayfinding dos participantes diante de protótipos de sinalização posicionados ao longo de rotas pré-estabelecidas em um dos blocos da instituição; b) utilizar a validação dos protótipos para reconhecer falhas e aspectos positivos nesses, em relação à legibiFigura 16. Esquema lidade, cor, tamanho, forma, posicionamento em relação da coleta de dados aos demais protótipos de sinalização, texto (Impresso ou Braille) e diagramação. para a segunda etapa. Fonte: Cunha, 2019. 
Figura 17. Participante lendo placas. Fonte:

Cunha, 2019

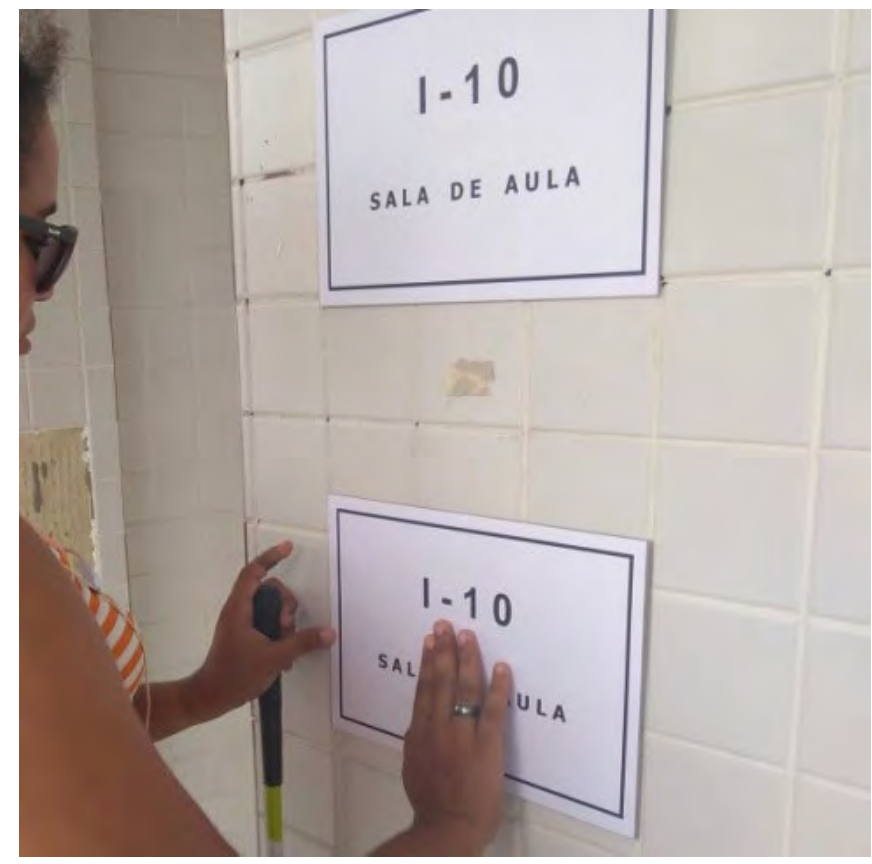

Quanto ao comportamento de wayfinding, diante dos protótipos de sinalização, os dados apontaram que: (1) todos tiveram algum tempo com os mapas e fizeram as suas estratégias de navegação, neste aspecto, todos apresentaram pouca dificuldade; (2) todas as rotas dentro do Bloco K/I definidas pelo segundo walkthrough foram executados com pouca dificuldade (exceto os banheiros). Nelas, os participantes realizaram os objetivos pedidos, não demonstraram desconforto, não se perderam e poucos pediram ajuda, assim como, todos os protótipos de sinalização foram encontrados e lidos sem dificuldades; (3) todos relataram muita desorientação durante a busca pelos banheiros e essas foi a segunda tarefa mais difícil para os participantes; (4) entrar e sair da edificação foram verbalizadas como as tarefas mais difíceis, e sair da edificação foi dada como mais difícil do que chegar. 


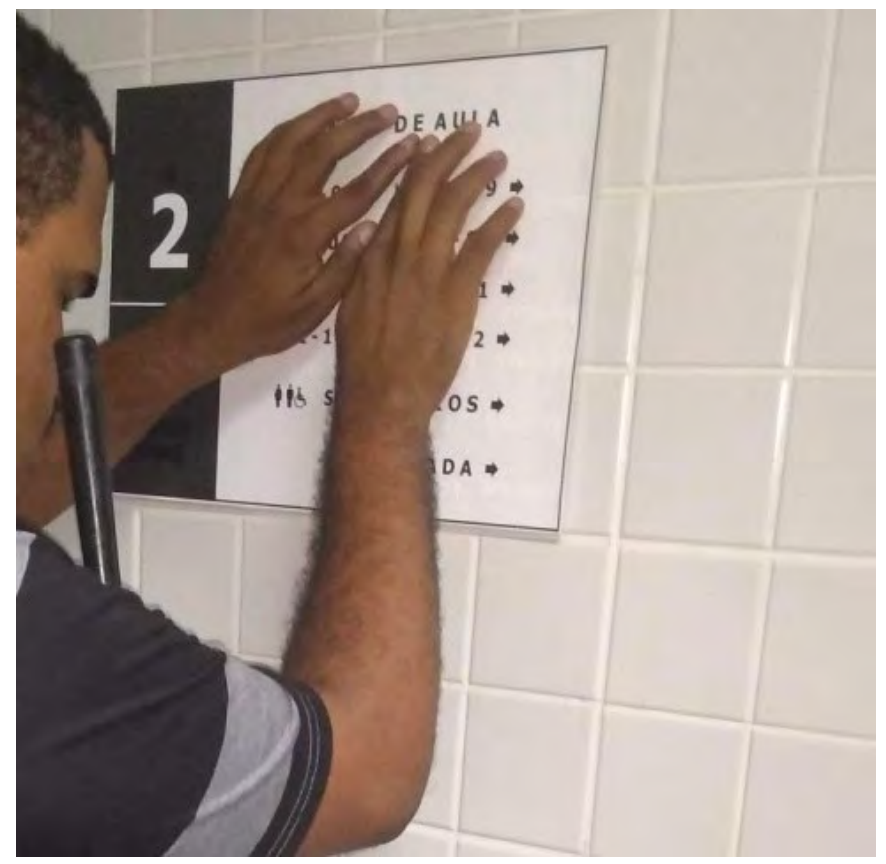

Figura 18. Participante lendo placa diretório. Fonte: Cunha, 2019

\section{Quanto ao reconhecimento de falhas e} aspectos positivos nos protótipos, os resultados foram agrupados em dois grupos: 0 primeiro, formado pelos participantes com cegueira congênita ou adquirida; e o segundo grupo, pelos participantes com baixa-visão.

$O$ resultado obtido no primeiro grupo foi que as placas dos banheiros foram as que mais receberam avaliações negativas, principalmente no critério de localização. Todos os participantes desse grupo sugeriram que as placas deveriam ficar em uma posição perpendicular à porta e não em uma posição paralela a esta.

O segundo grupo apresentou o mesmo posicionamento do primeiro, quanto às placas dos banheiros, em relação à localização: para eles, as placas deveriam estar posicionadas de frente para o corredor e não ao lado das portas. Também questionaram a cor e as dimensões, que deveriam ser maiores e com tons mais vibrantes. 


\section{DISCUSSÃO}

Diante do exposto, a discussão desta pesquisa apresenta quatro vieses a serem observados:
A. o primeiro diz respeito ao com- portamento de wayfinding em um ambiente com falhas ou ausência de sinalização;
B. o segundo refere-se ao comporta- mento de wayfinding diante de um sistema de sinalização dimensio- nado, baseado nas reais necessi- dades informacionais do usuário;
C. os aspectos físicos que interferem no wayfinding, não apenas em avaliações pós-ocupação; mas, principalmente, em etapas proje- tuais de ambientes construídos;
D. a importância do mapa tátil em um sistema de sinalização.

Quanto ao primeiro, pode-se afirmar que as circulações mal definidas e ausência de referências espaciais contribuíram de igual forma com a ausência de sinalização gráfica para o deslocamento insatisfatório pelas rotas sugeridas. Munidos de mapas táteis, os participantes puderam compreender o ambiente e realizar suas estratégias de navegação. Porém, na execução das rotas e identificação do destino final, o mapa-tátil não foi suficiente para munir os participantes com as informações ao longo dos trajetos. 


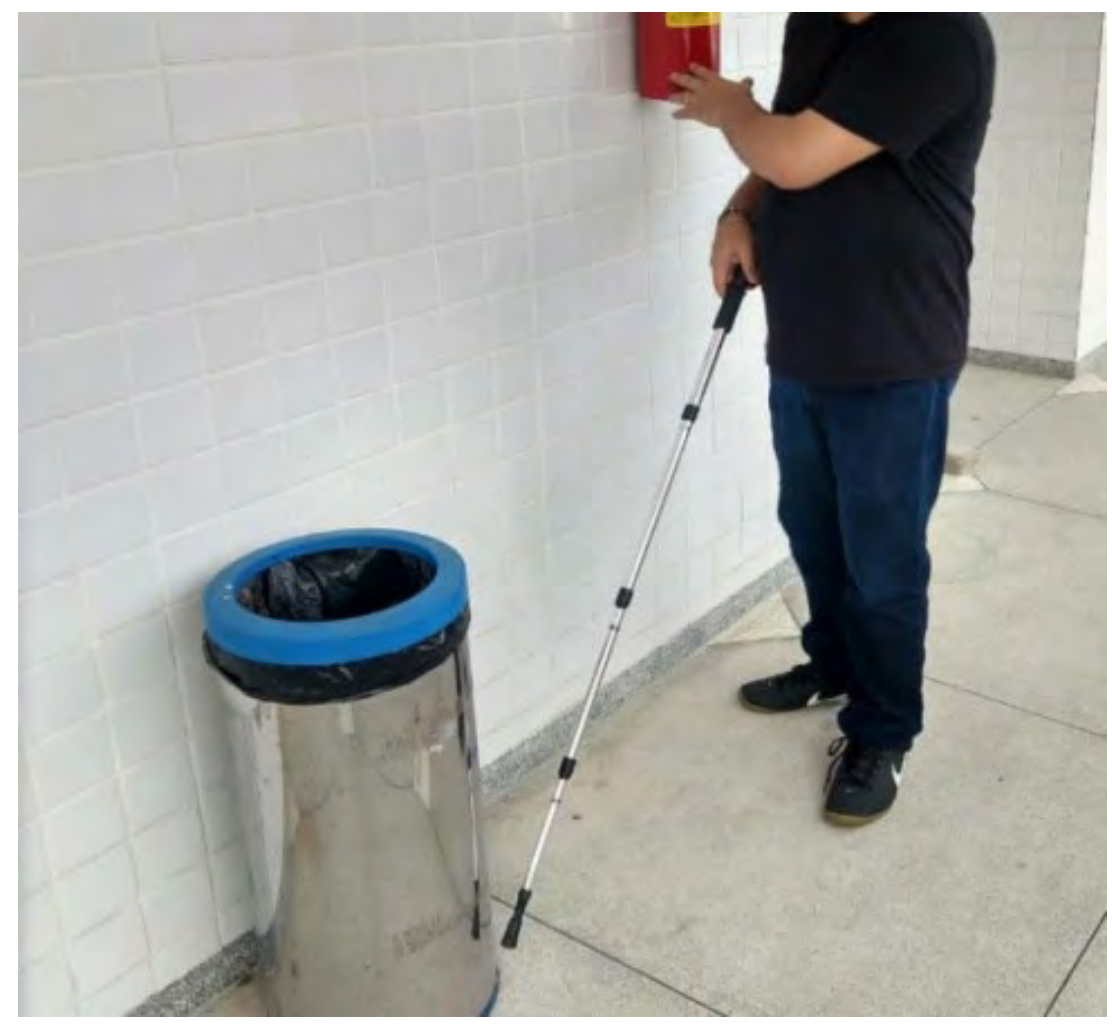

Figura 19. Participante e aspectos físicos no trajeto. Fonte: Cunha, 2019

Quanto ao segundo viés a ser observado, pode-se afirmar: que diante de rotas com um sistema de sinalização dimensionado conforme a necessidade de informação do usuário e do ambiente, os participantes apresentaram poucas dificuldades e se deslocaram com autonomia ao longo dos trajetos.

Assim como na situação anterior, os voluntários foram munidos de mapas-táteis, porém, neste momento, os mapas-táteis fizeram parte do sistema proposto, dialogando e mantendo uma relação de hierarquia com os demais protótipos de sinalização. Dessa forma, foram amplamente utilizados para a elaboração de estratégias de navegação - como suporte - em caso de dúvidas nas etapas de execução da rota e identificação do destino.
Por um lado, quanto ao terceiro viés, é importante observar que em ambas as etapas, existiram aspectos físicos (de layout do lugar e expressões gráficas) que interferiram no processo de wayfinding dos participantes. Porém, quando diante de um ambiente sinalizado, as dificuldades foram brevemente superadas, por meio de consultas aos mapas-táteis ou apenas por breves questionamentos direcionados aos pesquisadores durante a realização do experimento.

Por outro lado, tais aspectos influenciaram profundamente no processo de wayfinding quando os participantes não encontravam pistas, sinalizações gráficas e referências espaciais de qualquer tipo, ao longo do caminho, gerando sentimentos de insatisfação, frustração e de incapacidade, relatados por alguns deles. 
Figura 20. Participante lendo mapa-tátil.

Fonte: Cunha, 2019

Figura 21. Participante lendo mapa-tátil.

Fonte: Cunha, 2019
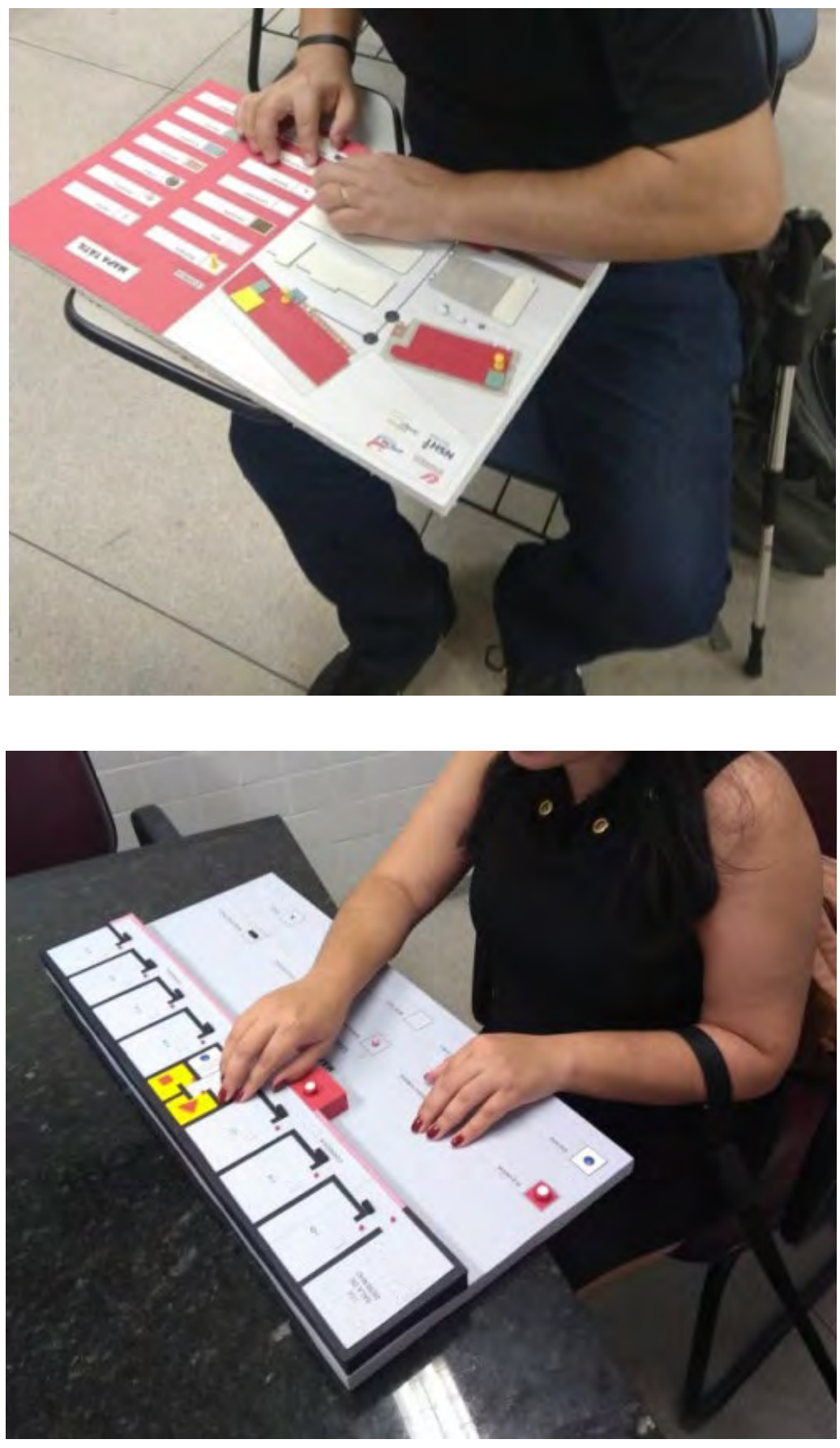

Por fim, como desdobramento da pesquisa, pode-se observar a importância do papel realizado pelo mapa-tátil dentro do sistema de sinalização. Sendo este, muitas vezes, o 
primeiro contato do usuário com a configuração espacial do ambiente, tornando viável a criação de mapas mentais e compreensão das informações úteis para a execução de trajetos. Com isso, pode-se afirmar que a presença dos mapas-táteis afetou sensivelmente a realização de ambas as etapas.

\section{CONCLUSÃO}

Esta pesquisa apontou a ausência ou fragilidades na acessibilidade informacional como um dos obstáculos que justificam o baixo número de acesso de pessoas - com deficiência visual - ao ambiente de ensino superior no Brasil. Nesse sentido, teve o objetivo de sugerir o wayfinding como auxílio ao deslocamento dessas pessoas nesses ambientes por meio de um estudo de caso realizado na Escola Politécnica da Universidade de Pernambuco (Poli/UPE).

Para isso, esta pesquisa baseou-se no conceito proposto por Arthur e Passini (2002), de que o wayfinding é um processo dinâmico (entre tomadas de decisão, execução de tomadas de decisão e processamento da informação) e influenciado por fatores humanos (capacidade de percepção e habilidades cognitivas) além de fatores ambientais (layout do lugar e expressões gráficas).

Sendo assim, para compreendê-lo como auxílio às pessoas com deficiência visual, fez-se necessário o direcionamento desta pesquisa para a análise dos fatores humanos (comportamento de wayfinding) e ambientais (aspectos físicos) que influenciam nos processos de wayfinding desses indivíduos. Ou seja, buscou-se compreender como pessoas com deficiência visual deslocam-se e encontram seus caminhos em trajetos, diante dos aspectos físicos apresentados pelo ambiente construído ao longo de todo o deslocamento.

Portanto, quanto ao comportamento de wayfinding de pessoas com deficiência visual, os resultados desta pesquisa corroboram com Zimring e Templer (1983), quanto às estratégias de orientação desses indivíduos. Segundo tais autores, essas estratégias são: (1) memorizar pontos de referência a cada rota e depois ligá-los sem que, necessariamente, exista uma relação entre eles; (2) memorizar todos os principais pontos de referência e ligá-los no intuito de formar um panorama geral do lugar por meio da elaboração de um mapa mental. 
Assim como confirmam os experimentos de Passini e Proulx (1988) quando afirmam que o comportamento de pessoas com deficiência visual cria estratégias de navegação por meio de mapas mentais, porém, necessitam de um número maior de referências espaciais para executar suas estratégias.

Nesse sentido, observa-se que o comportamento de wayfinding de pessoas com deficiência visual está diretamente relacionado aos aspectos físicos, sejam os encontrados no ambiente - como parte da sua configuração - ou aqueles representados em elementos gráfico-táteis de sinalização.

Portanto, com os resultados encontrados nesta pesquisa, afirma-se que o wayfinding auxilia no deslocamento de pessoas com deficiência visual em ambientes construídos, quando são propostas ferramentas de comunicação alinhadas às especificidades desse público. No entanto, para isso, é necessário que tais ambientes sejam planejados ou reformados com um olhar atento $e$ crítico ao equilíbrio entre os aspectos físicos e os aspectos humanos que compõem a própria dinâmica do wayfinding. 


\section{REFERÊNCIAS}

ARTHUR, P.; PASSINI, R. Wayfinding: people, signs, and architecture. 2nd ed. Arlington: McGraw-Hill, 2002.

CALORI, C.; VANDEN-EYNDEN, D. Signage and Wayfinding Design: A Complete Guide to Creating Environmental Graphic Design Systems. 2nd. ed. New Jersey: Wiley, 2015.

CARPMAN, J. R.; GRANT, M. A. Wayfinding: A broad view. In: BECHTEL, R. B.; CHURCHMAN, A. (Ed.). Handbook of environmental psychology. New York: John Wiley, 2002, p. 427-443.

COSTA, J. Señalética corporativa. Barcelona: Costa Punto Com, 2007.

CUNHA, S. C. Wayfinding como auxílio ao deslocamento da pessoa com deficiência visual. 2019. 304 f. Dissertação (Mestrado) - Programa De Pós-Graduação Design, Universidade Federal de Pernambuco, Recife.

GIBSON, D. The Wayfinding Handbook: Information Design for Public Places. New York: Princeton Architectural Press, 2009.

GIL, A. C. Como elaborar projetos de pesquisa. São Paulo: Atlas, 2002.

INSTITUTO NACIONAL DE ESTUDOS E PESQUISAS EDUCACIONAIS ANÍSIO TEIXEIRA.

\section{Sinopse Estatística da Educação Básica}

2016. Brasília: Inep, 2017. Sinopse

Estatística da Educação Superior 2016.

Brasília: Inep, 2017.
INSTITUTO BRASILEIRO DE GEOGRAFIA E ESTATÍSTICA. Pesquisa Nacional de Saúde. Rio de Janeiro: IBGE, 2013.

MOLLERUP, P. Wayfinding>Wayshowing. Amsterdam: BIS Publishers, 2013.

MONT'ALVÃO, C. R.; RANGEL, M. M. A observação do comportamento do usuário para o wayfinding no ambiente construído. Estudos em Design, Rio de Janeiro, v. 23, n. 3, p. 166-180, 2015.

PASSINI, R.; PROULX, G. Wayfinding Without Vision. Environment and Behavior, LoS Angeles, 1988, v. 20, n. 2, p. 227-252, Mar. 1998.

ZIMRIG, C.; TEMPLER, J. Wayfinding and orientation by the visually impaired. Journal of Environmental Systems, Amityville, v. 13, n. 4, pp. 333-352, Jan. 1983. 


\section{NOTA}

Esta pesquisa parte da dissertação de mestrado da autora (CUNHA, 2019), integrando-se como parte do projeto de pesquisa aprovado e financiado pelo Conselho de Desenvolvimento Científico e Tecnológico (CNPq) intitulado "Acessibilidade física, perceptiva, cognitiva e informacional visando favorecer a mobilidade da pessoa com deficiência (PcD) em instituições de ensino superior" pela Escola Politécnica da Universidade de Pernambuco (Poli/UPE) por meio do Núcleo de Segurança e Higiene do Trabalho (NSHT) e com a participação da Universidade Federal de Pernambuco (UFPE) por meio do Laboratório de Ergonomia do departamento de Design (Labergo). Considerando a Resolução 466/12 do CNS sobre protocolos de pesquisas que envolvem seres humanos e a definição de "risco" em seu inciso II-22, aponta-se o projeto delimitado nesse documento como uma pesquisa não invasiva, de risco mínimo, devido a não realização de nenhuma intervenção ou modificação nas estruturas fisiológicas, psicológicas/ emocionais, intelectuais, socioculturais e/ou econômicas dos indivíduos que participaram do estudo. Considerando tais riscos mínimos foram tomados os seguintes posicionamentos: todas as respostas são confidenciais; os questionários e formulários de perguntas podem não ser identificados pelo nome, caso deseje o participante, garantindo o anonimato; foi realizada a leitura do TCLE para todos os participantes com abertura para quaisquer esclarecimentos necessários; treinamento com pesquisadores da equipe para realização dos experimentos; questionários e instrumentos de pesquisa disponibilizados para diferentes tipos de restrição/dificuldade comunicacional/ sensorial; garantia de sigilo de informações coletadas; o experimento nas pesquisas de campo foi realizado com a presença, durante todo o trajeto, de pesquisadores; participação voluntária, podendo ter interrompida a qualquer momento; consideração de situação de vulnerabilidade, se houvesse. 